DD

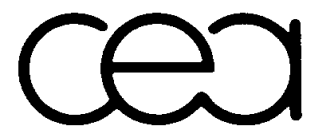

C.E. SACLAY
DSM
DAPNIA 94.01 Sw 9408
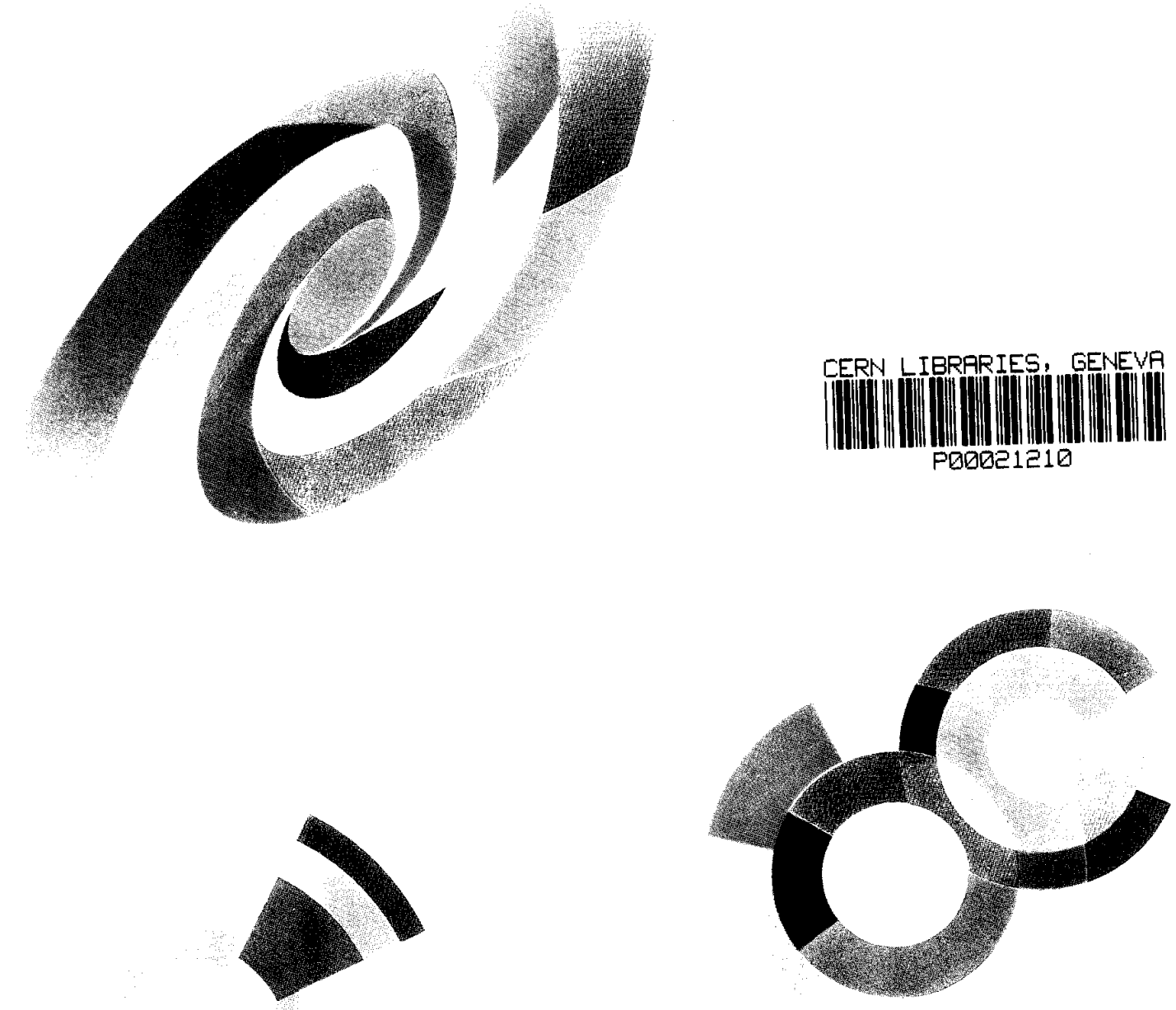

DAPNIA/94-01

January 1994

BEHAVIOUR OF $\mathrm{CeF}_{3}$ SCINTILLATOR IN A LHC-LIKE ENVIRONMENT

R. CHIPAUX, J.-L. FAURE, P. REBOURGEARD

D)ADNDA

G. DAUPHIN, J. SAFIEH 
Le DAPNIA (Département d'Astrophysique, de physique des Particules, de physique Nucléaire et de l'Instrumentation Associée) regroupe les activités du Service d'Astrophysique (SAp), du Département de Physique des Particules Elémentaires (DPhPE) et du Département de Physique Nucléaire (DPhN).

Adresse : $\quad$ DAPNIA, Bâtiment 141

CEA Saclay

F - 91191 Gif-sur-Yvette Cedex 


\title{
Behaviour of $\mathrm{CeF}_{3}$ scintillator in a $\mathrm{LHC}$-like environment *
}

\author{
R. Chipaux, J.-L. Faure, P. Rebourgeard \\ DAPNIA, CEA Saclay, France \\ G. Dauphin, J. Safieh \\ INSTN/SENE, CEA Saclay, France
}

\begin{abstract}
.
The neutron radiation resistance of a sample of cerium fluoride has been investigated with the reactor ULYSSE. The fast, thermal and epithermal neutron fluxes and the gamma dose rate at the irradiation position have been determined. The overall irradiation conditions are analogous to the condition foreseen in the future electromagnetic calorimeters for high energy physics. The effect of neutron radiation on the transmission and photoluminescence properties has been studied up to a fast neutron fluence of $10^{14}$ neutrons $/ \mathrm{cm}^{2}$. The respective damage effect of gamma rays, thermal neutrons and fast neutrons is discussed, as well as the induced radioactivity observed.
\end{abstract}

\section{Résumé.}

La résistance aux neutrons d'un échantillon de fluorure de cérium a été étudiée avec le réacteur ULYSSE. Les flux de neutrons rapides, thermiques et épithermiques ainsi que le débit de dose gamma au point d'irradiation ont été déterminées. L'ensemble des conditions d'irradiation est analogue à ce qui est attendu dans les futurs calorimètres électromagnétiques pour la physique des hautes énergies. L'effet des neutrons sur les propriétés de transmission optique et de photoluminescence a été étudié jusqu'à une fluence de $10^{14}$ neutrons rapides $/ \mathrm{cm}^{2}$. L'effet respectif des photons gamma, des neutrons thermiques et des neutrons rapides est discutée, ainsi que la radioactivité induite observée.

Soumis à

Nuclear Instruments \& Methods in Physics Research A

26 janvier 1994

* This work has been carried out in the frame of the «Crystal Clean» collaboration, CERN Research and Development project RD-18. 


\section{•}




\section{Introduction.}

Cerium fluoride is one of the possible crystal scintillator candidates for high rate electromagnetic calorimetry. A large research and development effort has been undertaken to evaluate precisely its properties, particularly within the «Crystal Clean) collaboration [1]. It has been presented as an option for the electromagnetic calorimeter of the CMS experiment proposed for the Large Hadron Collider in project at CERN [2] Table 1 recalls its main characteristics compared to other scintillating crystals.

Among other specifications to fulfil for an electromagnetic calorimeter in the experiments proposed for the Large Hadron Collider, radiation resistance is imperative [3]. For example, in the CMS electromagnetic calorimeter, the highest ionisation damage will be observed at the maximum of the electromagnetic cascade. The yearly dose (assuming 1 year $\approx 10^{7} \mathrm{~s}$ of operation) is expected to vary from $1 \mathrm{kGy}$ in the central part $(\eta=0)$ to $40 \mathrm{kGy}$ in the forward region $(\eta=2.6)$ [2]. The hadron fluence per year will range from $2.10^{12} 1 \mathrm{MeV}$ equivalent neutrons $/ \mathrm{cm}^{2}$ at $\eta=0$ to $4.10^{13}$ neutrons $/ \mathrm{cm}^{2}$ at $\eta=2.6[4]$.

We present here results on fast neutron resistance of a $\mathrm{CeF}_{3}$ sample produced by Optovac (USA). It's size is $9.5 \times 15.5 \times 19.5 \mathrm{~mm}^{3}$. As reported in [5], this sample, (labelled CF 128), has been irradiated in a first phase by ${ }^{60} \mathrm{Co}$ gamma photons, at a low dose rate, during about 6 months. The total absorbed dose was $5.3 \pm 1.1 \mathrm{kGy}(530 \pm 110 \mathrm{krad})$ at an average rate of $1.2 \mathrm{~Gy} / \mathrm{h}(120 \mathrm{rad} / \mathrm{h})$. No damage was observed in the transmission properties after this irradiation. A crystal of the same production batch was irradiated at high dose rate at Frascati, up to $100 \mathrm{kGy}(10 \mathrm{Mrad})$ with no noticeable damage [6].

Table 1.: Properties of $\mathrm{CeF}_{3}$ and other dense scintillating crystals.

\begin{tabular}{lccccccc} 
crystal & $\mathrm{CsI}$ & $\mathrm{BaF}_{2}$ & $\mathrm{CeF}_{3}$ & $\mathrm{GSO}$ & $\mathrm{BGO}$ & $\mathrm{PbWO}_{4}$ & $\mathrm{PbF}_{2}$ \\
\hline density $\left(\mathrm{g} / \mathrm{cm}^{3}\right)$ & 4.51 & 4.89 & 6.16 & 6.71 & 7.13 & 8.28 & 7.77 \\
\hline radiation length $(\mathrm{cm})$ & 1.86 & 2.03 & 1.65 & 1.38 & 1.12 & 0.89 & 0.94 \\
\hline Molière radius $(\mathrm{cm})$ & 3.5 & 3.39 & 2.63 & 2.42 & 2.24 & 2.2 & 2.22 \\
\hline decay time $(\mathrm{ns})$ & 16 & 0.6 & 5 & 60 & 300 & 2.5 & Cerenkov \\
& 1000 & 620 & 30 & & & 11 & \\
\hline peak emission $(\mathrm{nm})$ & 315 & 210 & 300 & 440 & 480 & 420 & 300 \\
\hline refractive index & 565 & 310 & 340 & & & 520 & (cut-off) \\
(at peak emission) & 1.95 & 1.55 & 1.62 & 1.85 & 2.15 & 2.25 & 1.93 \\
light output & 1.79 & 1.50 & & & & & \\
(photons/MeV) & 2000 & 2500 & 2000 & 10000 & 10000 & 200 & 1.3 \\
& & 6500 & & & & & \\
\hline
\end{tabular}




\section{Experimental Conditions.}

After the low rate gamma irradiation, the sample CF128 was exposed in the nuclear reactor ULYSSE of the Institut National des Sciences et Techniques Nucleaires (INSTN) in Saclay. This small U-metal reactor is mainly dedicated to training purposes. Its great advantage is the possibility to monitor its power over 5 orders of magnitude (from 1 to $10^{5} \mathrm{~W}$ ) and thus to vary the neutron fluxes in the same proportions [7].

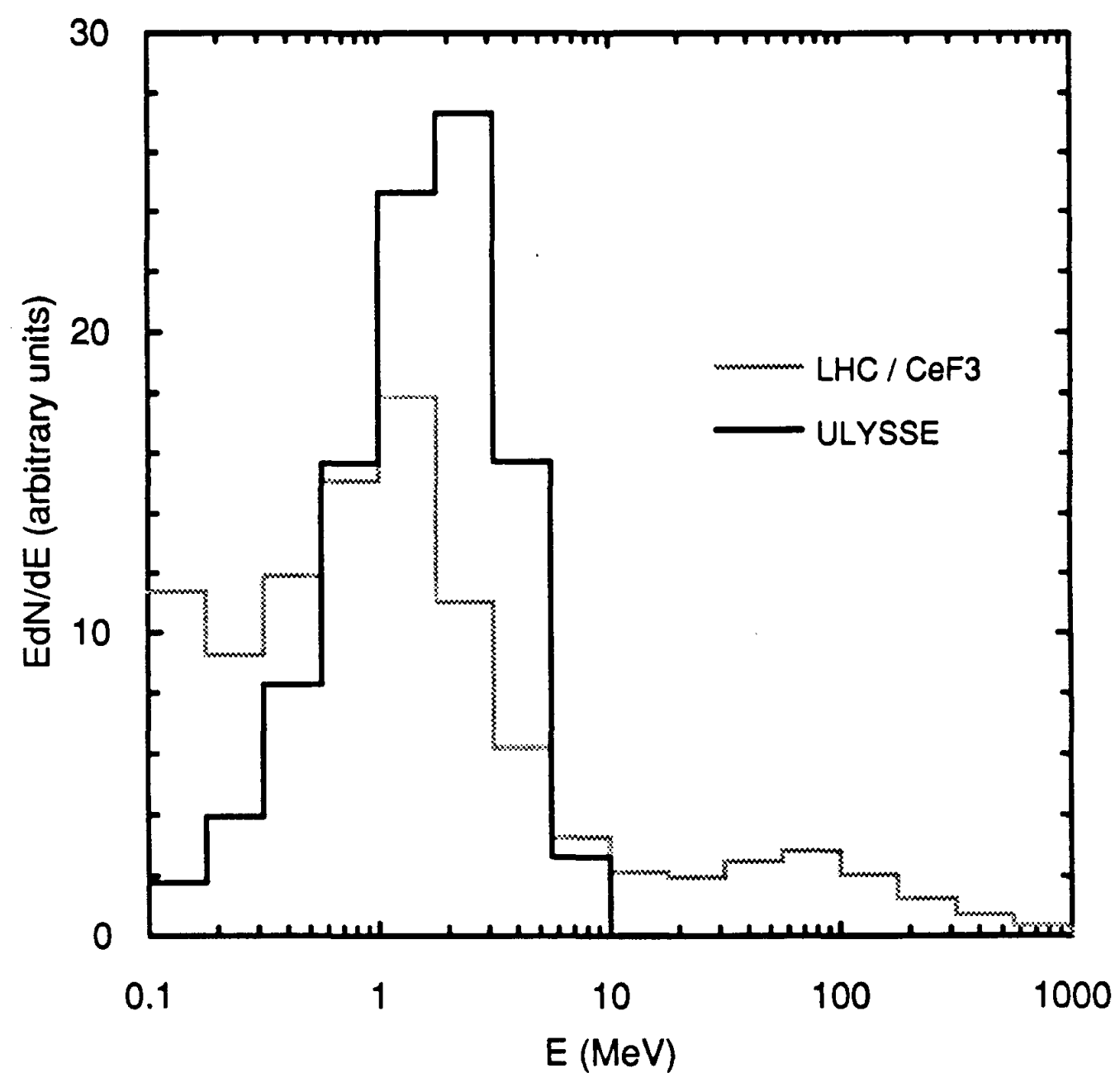

Figure 1.: Neutron spectra in a $\mathrm{CeF}_{3}$ calorimeter with moderator, as calculated in ref. [4] and neutron spectrum in the channel $\mathrm{HN} 1$ of the reactor ULYSSE. The spectra are normalised to give the same total fluence between $100 \mathrm{keV}$ and $1 \mathrm{GeV}$. 
For our measurement we used the channel ' $\mathrm{HNl}$ ', which allows to put the samples almost in contact with the fuel elements. In that position, the fast neutron spectrum is close to the uranium 235 fission one, which can be parametrized, for $0.1 \leq E \leq 12 \mathrm{MeV}$, by $\phi(E)=0.454 \exp (-E / 0.965) \sinh (\sqrt{2.29 E})$, where $E$ is the neutron energy in $\mathrm{MeV}$ [8].

During the same period of time, the fast neutron, thermal neutron and epithermal neutron fluxes were measured by a thin foil activation method [9], with various metals ( $\mathrm{Au}, \mathrm{In}, \mathrm{Ni}$ ). At the position of irradiation the measures give $2.4 \pm 0.510^{6}$ neutrons $/ \mathrm{cm}^{2} / \mathrm{s} / \mathrm{W}$ for fast neutrons $(E>100 \mathrm{keV}), 8 . \pm 2.10^{6}$ neutrons $/ \mathrm{cm}^{2} / \mathrm{s} / \mathrm{W}$ for epithermal neutrons $(100 \mathrm{keV}>E>1 \mathrm{eV})$ and 7. $\pm 2.10^{6}$ neutrons $/ \mathrm{cm}^{2} / \mathrm{s} / \mathrm{W}$ for thermal neutrons $(E<1 \mathrm{eV})$. The gamma dose rate was measured with an ionisation chamber and is estimated to $3 . \pm 1.10^{-4} \mathrm{~Gy} / \mathrm{s} / \mathrm{W}$. Hence the ratio of gamma dose versus fast neutron fluence $\left(1.25 \mathrm{kGy} . \mathrm{cm}^{2} / 10^{13}\right.$ neutrons) in ULYSSE is well in the range of the one foreseen in the proposed CMS electromagnetic calorimeter.

The fast neutron fluence delivered in ULYSSE is similar in shape to the neutron fluence in a high energy electromagnetic calorimeter, with a peak around $1 \mathrm{MeV}$. For example, Figure 1 compares it to the neutron spectrum calculated by Aarnio and Huhtinen for the $\mathrm{CeF}_{3}+$ moderator option of the CMS electromagnetic calorimeter (Figure $4 \mathrm{~b}$ in ref. [4]). The epithermal fluences, not shown in the figure, are also analogous, the ratio between fast and epithermal fluences being 0.30 in ULYSSE and 0.34 in the $\mathrm{CeF}_{3}+$ moderator option of CMS.

Thus we can consider the irradiation conditions as well representative of the environment of the proposed crystal electromagnetic calorimeter.

A cumulated fluence of $1.0 \pm 0.210^{14}$ fast neutrons $/ \mathrm{cm}^{2}$ was reached in 7 steps. The fast neutron flux ranged from $2.410^{6}$ neutrons $/ \mathrm{cm}^{2} / \mathrm{s}$ to $1.410^{10}$ neutrons $/ \mathrm{cm}^{2} / \mathrm{s}$. For comparison, the flux is estimated to vary from $2.10^{5}$ neutrons $/ \mathrm{cm}^{2} / \mathrm{s}$ at $\eta=0$ to $4.10^{6}$ neutrons $/ \mathrm{cm}^{2} / \mathrm{s}$ at $\eta=2.6$ in the CMS electromagnetic calorimeter [4]. The irradiation conditions and the doses received are reported in Table 2 . For radiation protection reasons, the transmission and photoluminescence spectra were recorded on average four days after irradiation. The sample was kept out of light during this time.

Table 2. : Characteristics of the irradiation steps.

date of power duration fast neutrons fluence thermal neutrons

irradiation (W) (min) $\quad\left(\mathrm{n} / \mathrm{cm}^{2}\right)$ fluence $\left(\mathrm{n} / \mathrm{cm}^{2}\right)$

gamma dose cumulated cumulated

(Gy) cumulated

\begin{tabular}{|c|c|c|c|c|c|c|c|c|}
\hline $92 / 06-12$ & & & ow rate $\mathrm{g}$ & mma irrad & tion) & & 5300 & 5300 \\
\hline $93 / 03 / 18$ & 1 & 14 & $2.010^{9}$ & $2.010^{9}$ & $5.910^{9}$ & $5.910^{9}$ & 0.25 & 5300 \\
\hline $93 / 03 / 22$ & 10 & 28 & $4.010^{10}$ & $4.210^{10}$ & $1.210^{11}$ & $1.210^{11}$ & 5.0 & 5300 \\
\hline $93 / 03 / 26$ & 100 & 70 & $1.010^{12}$ & $1.110^{12}$ & $2.910^{12}$ & $3.110^{12}$ & 126 & 5400 \\
\hline $93 / 04 / 09$ & 300 & 70 & $3.010^{12}$ & $4.110^{12}$ & $8.810^{12}$ & $1.210^{13}$ & 380 & 5800 \\
\hline $93 / 04 / 22$ & 600 & 70 & $6.010^{12}$ & $1.010^{13}$ & $1.810^{13}$ & $3.010^{13}$ & 760 & 6600 \\
\hline $93 / 04 / 30$ & 2000 & 70 & $2.010^{13}$ & $3.010^{13}$ & $5.910^{13}$ & $8.810^{13}$ & 2500 & 9100 \\
\hline $93 / 05 / 07$ & 6000 & 80 & $6.910^{13}$ & $9.910^{13}$ & $2.010^{14}$ & $2.910^{14}$ & 8600 & 17700 \\
\hline
\end{tabular}




\section{Results.}

\subsection{Transmission.}

As shown in Figure 2, a small degradation in the transmission properties is observed after the first steps (curves $a, b, c$ ). Then no variation occurred up to $10^{13}$ neutrons $/ \mathrm{cm}^{2}$ (curves $\mathrm{c}$ to $\mathrm{f}$ ). A more significant degradation is observed for the highest fluences (curves $\mathrm{g}, \mathrm{h}$ ). The radiation induced absorption coefficient $\varepsilon(\lambda, \Phi)$ is defined by $T(\lambda, \Phi)=T(\lambda, 0) \exp (-\varepsilon(\lambda, \Phi) x)$, where $T(\lambda, \Phi)$ is the optical transmission measured along the same path for the different wavelengths $\lambda$ and fluences $\Phi$ (or doses in case of gamma irradiation) and $x$ the path length. The radiation induced attenuation length is the inverse of the absorption coefficient : $l_{\text {atr }}(\lambda, \Phi)=1 / \varepsilon(\lambda, \Phi)$. Table 3 indicates the values of the absorption coefficient at the three emission peaks for the different fluences. Owing to the small length of the crystal, the values of the radiation-induced absorption coefficients are rather imprecise. Incertitudes are calculated assuming absolute errors of 0.008 in the transmission measurements and $0.2 \mathrm{~mm}$ in the path length.

Table 3. : Radiation-induced absorption coefficients at the wavelengths of the emission peaks.

\begin{tabular}{lccc} 
wavelength & $286 \mathrm{~nm}$ & $303 \mathrm{~nm}$ & $340 \mathrm{~nm}$ \\
\hline after irradiation 1 & $0.6 \pm 1.2 \mathrm{~m}^{-1}$ & $0.7 \pm 0.7 \mathrm{~m}^{-1}$ & $0.7 \pm 0.6 \mathrm{~m}^{-1}$ \\
\hline after irradiation 2 & $0.8 \pm 1.2 \mathrm{~m}^{-1}$ & $1.4 \pm 0.7 \mathrm{~m}^{-1}$ & $1.2 \pm 0.6 \mathrm{~m}^{-1}$ \\
\hline after irradiation 3 & $-0.6 \pm 1.2 \mathrm{~m}^{-1}$ & $1.3 \pm 0.7 \mathrm{~m}^{-1}$ & $1.2 \pm 0.6 \mathrm{~m}^{-1}$ \\
\hline after irradiation 4 & $1.8 \pm 1.2 \mathrm{~m}^{-1}$ & $1.3 \pm 0.7 \mathrm{~m}^{-1}$ & $1.1 \pm 0.6 \mathrm{~m}^{-1}$ \\
\hline after irradiation 5 & $2.6 \pm 1.3 \mathrm{~m}^{-1}$ & $1.3 \pm 0.7 \mathrm{~m}^{-1}$ & $1.3 \pm 0.6 \mathrm{~m}^{-1}$ \\
\hline after irradiation 6 & $1.8 \pm 1.2 \mathrm{~m}^{-1}$ & $2.1 \pm 0.7 \mathrm{~m}^{-1}$ & $2.0 \pm 0.7 \mathrm{~m}^{-1}$ \\
\hline after irradiation 7 & $5.1 \pm 1.3 \mathrm{~m}^{-1}$ & $3.8 \pm 0.7 \mathrm{~m}^{-1}$ & $3.7 \pm 0.7 \mathrm{~m}^{-1}$ \\
\hline 27 days after irradiation 7 & $4.9 \pm 1.3 \mathrm{~m}^{-1}$ & $3.3 \pm 0.7 \mathrm{~m}^{-1}$ & $3.0 \pm 0.7 \mathrm{~m}^{-1}$ \\
\hline after UV exposure & $3.3 \pm 1.3 \mathrm{~m}^{-1}$ & $2.5 \pm 0.7 \mathrm{~m}^{-1}$ & $2.4 \pm 0.7 \mathrm{~m}^{-1}$
\end{tabular}

It is difficult to conclude if the effect observed for the lowest fluences is intrinsic and related to the irradiation or extrinsic and related to other causes like surface degradation. However this effect is small and saturates after the two first irradiation steps. At higher fluences, we can describe the evolution of the transmission as the sum of this constant term (either intrinsic or extrinsic) and a term proportional to the fluence, due to the irradiation (Figure 3). 


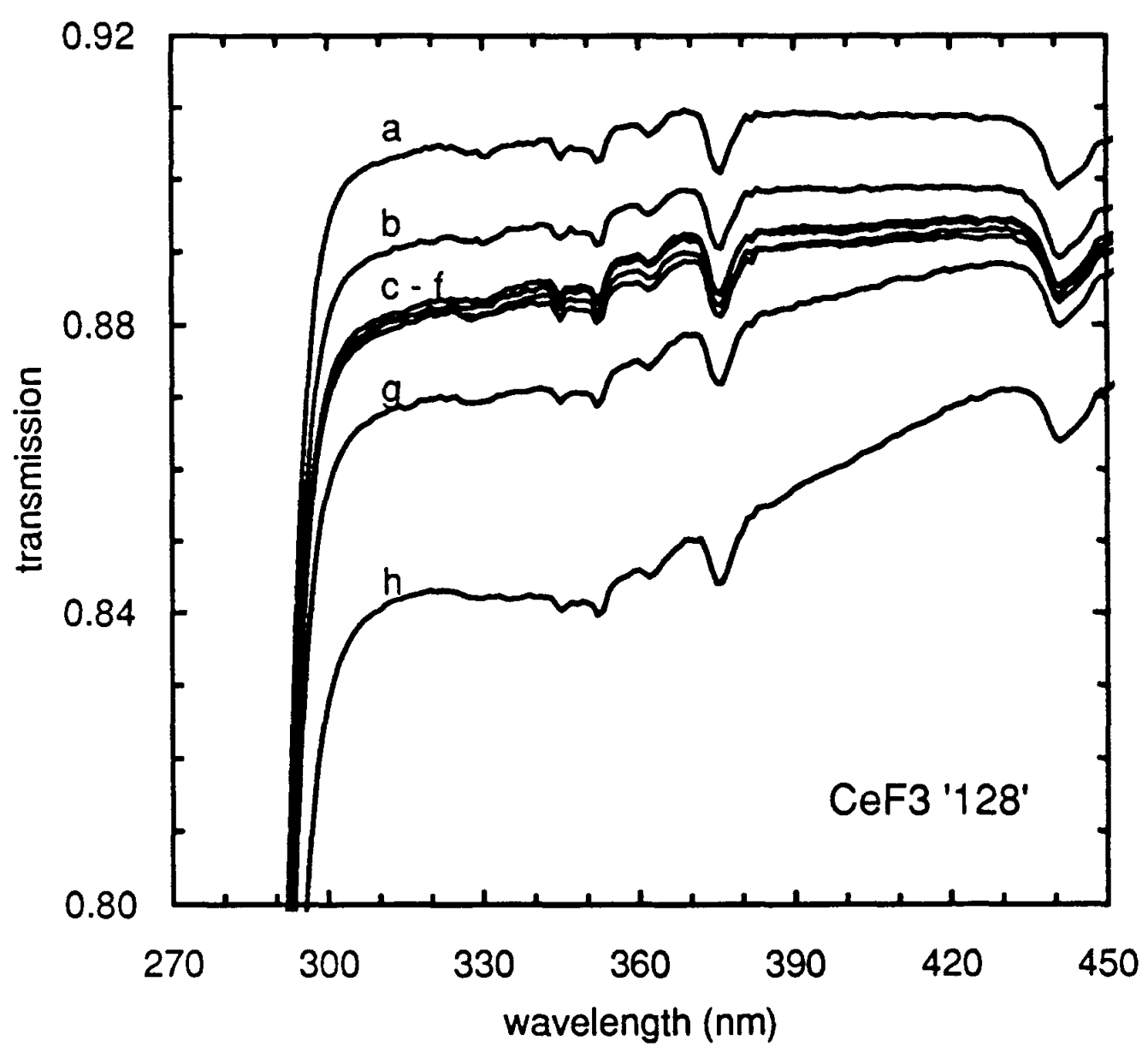

Figure 2. : Transmission, along $1.95 \mathrm{~cm}$, versus wavelength. (Note the magnified scale, the maximum effect being about $6 \%$ ) :

$\mathrm{a}:$ before irradiation, $\mathrm{b}:$ after $210^{9}$ neutrons $/ \mathrm{cm}^{2}, \mathrm{c}:$ after $4.210^{10}$ neutrons $/ \mathrm{cm}^{2}$, $\mathrm{d}:$ after $1.110^{12}$ neutrons $/ \mathrm{cm}^{2}$, e : after $4.110^{12}$ neutrons $/ \mathrm{cm}^{2}$,

$\mathrm{f}$ : after $1.010^{13}$ neutrons $/ \mathrm{cm}^{2}, \mathrm{~g}:$ after $3.010^{13}$ neutrons $/ \mathrm{cm}^{2}$,

$\mathrm{h}:$ after $10^{14}$ neutrons $/ \mathrm{cm}^{2}$. 


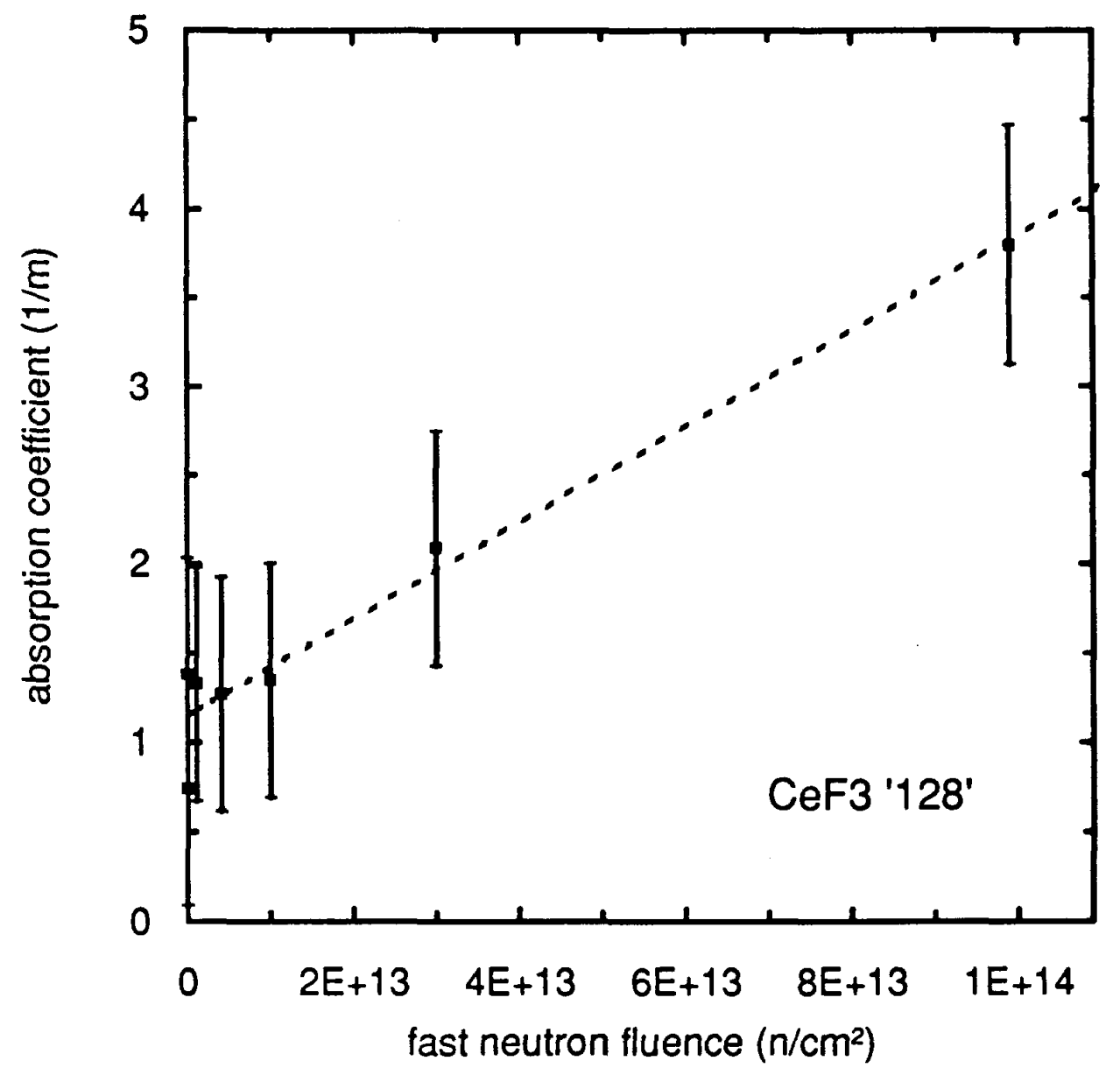

Figure 3. : Radiation-induced absorption coefficients at $303 \mathrm{~nm}$, as function of the neutron fluence.

Nevertheless the sample suffers at the same time from gamma photons, from fast and thermal neutrons. We presume that these effects are independent. We know from previous gamma irradiation tests $[5,6]$ that gamma radiation damage is negligible below $100 \mathrm{kGy}$. Two main effects can be attributed to the neutrons: activation and displacement. Activation is mostly due to the thermal neutrons, for which the absorption cross sections can be important. A very small proportion of the nuclei are affected at the fluence level reached here, and no effects are expected thereby in the optical or luminescence properties. Atomic displacement is related to the neutron energy, and may lead to the creation of color centres which induce light absorption, and so-called quenching centres, which affect the scintillator light yield. It is known that the fast neutrons are much more efficient that the less energetic epithermal neutrons. 
Thus we conclude that in that case the effects of gamma photons, thermal and epithermal neutrons are negligible, and that the radiation induced optical absorption is only caused by the fast neutrons. Then the neutron-induced absorption coefficient on various isotopes can be estimated to be $0.27 \pm 0.08 \mathrm{~m}^{-1}$ per $10^{13}$ fast neutrons $/ \mathrm{cm}^{2}$ at the peak of the emission spectrum $(303 \mathrm{~nm})$. This is equivalent to an induced absorption length of roughly $4 \mathrm{~m}$ at a fluence of $10^{13}$ fast neutrons $/ \mathrm{cm}^{2}$, or $40 \mathrm{~cm}$ at $10^{14}$ fast neutrons $/ \mathrm{cm}^{2}$.

A slight recovery (natural annealing) is observed four weeks after the last irradiation. Exposure to UV light increases this recovery but the sample does not fully recover it's initial transmission (Table 3).

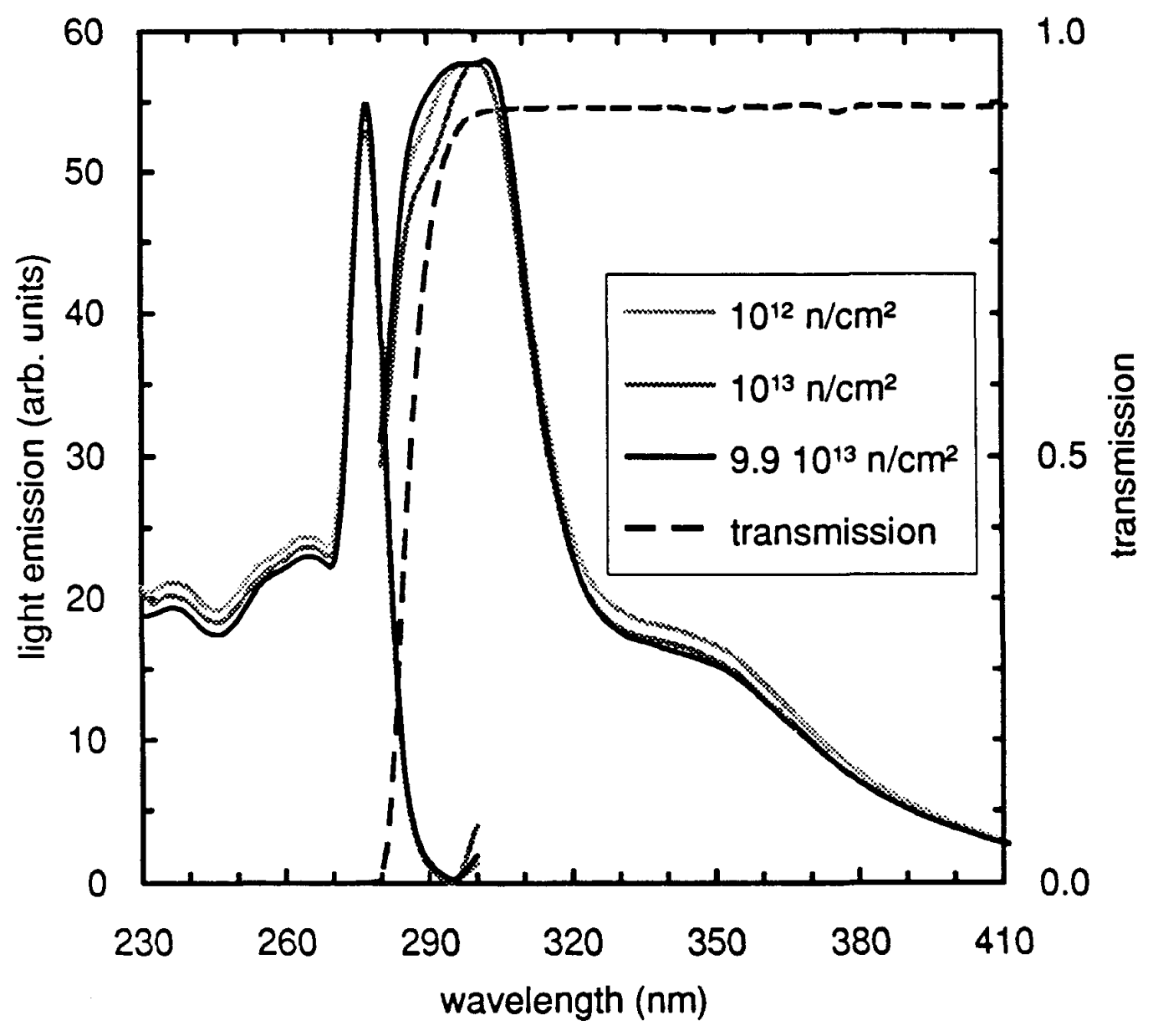

Figure 4. : Excitation spectra for a $303 \mathrm{~nm}$ emission (left curves) and emission spectra for a $277 \mathrm{~nm}$ excitation (right curves), and transmission before irradiation, as function of the wavelength. 


\subsection{Photoluminescence.}

The photoluminescence spectra are not particularly affected by the neutron irradiation, as shown in Figure 4. The excitation peak at $277 \mathrm{~nm}$ (for an emission at $303 \mathrm{~nm}$ ) does not vary in position, width or intensity. The background of excitation below $270 \mathrm{~nm}$ seems slightly reduced for the highest fluences. The emission spectrum shows the three usual peaks, near 286,303 and $340 \mathrm{~nm}$. The first peak, at $286 \mathrm{~nm}$, is just at the absorption edge, and its variation of intensity is not correlated with the irradiation but likely results from differences in the absorption due to surface quality variation. For the other peaks, above the absorption edge, no variation is observed.

\subsection{Activation.}

It should be noted that $\mathrm{CeF}_{3}$ is rather little activated by neutrons. The most abundant isotopes are ${ }^{140} \mathrm{Ce}$ and ${ }^{142} \mathrm{Ce}$, of natural abundance $88.43(10) \%$ and $11.13(10) \%$ respectively. They are activated in ${ }^{141} \mathrm{Ce}$ and ${ }^{143} \mathrm{Ce}$ by thermal neutron capture, with cross-sections of $0.58(4) \mathrm{b}$ and $0.95(1) \mathrm{b}$ respectively. ${ }^{141} \mathrm{Ce}$ decays in ${ }^{141} \mathrm{Pr}$ (stable) with a half-life of 32.5 days. ${ }^{143} \mathrm{Ce}$ decays with a half-life of 1.38 days in ${ }^{143} \mathrm{Pr}$, which itself decays with a half-life of 13.57 days in ${ }^{143} \mathrm{Nd}$ (stable). They all decay by $\beta$-emission [10]. The $\beta$-dose rate at the contact of the sample [11] was $250 \mu \mathrm{Gy} / \mathrm{h} 5$ days after the last irradiation, $60 \mu \mathrm{Gy} / \mathrm{h}$ after 27 days, and $1.4 \mu \mathrm{Gy} / \mathrm{h}$ after 192 days. This decrease is in good accordance with the calculation based on the nuclear data above mentioned.

\section{Conclusion.}

The ULYSSE Saclay reactor is a very suitable tool to study LHC detector material behaviour under radiation, such as crystal or plastic scintillator, photodetectors, electronics, etc. We are now using it routinely for such tests. From both ${ }^{60} \mathrm{Co}$ gamma irradiation and neutron reactor irradiation, we can conclude that for gamma doses below at least $50 \mathrm{kGy}(5 \mathrm{Mrad})$ and fast neutron fluences below at least to $5.10^{13} \mathrm{n} / \mathrm{cm}^{2}$, the $\mathrm{CeF}_{3}$ crystals can be used for electromagnetic calorimetry.

\section{Acknowledgements.}

The authors of this study are obliged to the entire team operating the ULYSSE reactor, without whom it could not have been made. We are grateful to $C$. Morin (CEA/DRN/SRO) and S. Alhilali for their help in the reactor flux calibration, and C. Aurouet, P.-H. Carton, and C. Jeanney (CEA/DAPNIA/SED) for the optical machining and measurements. We are indebted to all the members of the «Crystal Clean collaboration and particularly to P. Lecoq (CERN) for many useful meetings and enlightening discussions. We also want to thank $\mathrm{P}$. Micolon for his constant support and $\mathrm{H}$. Blumenfeld for his pertinent suggestions about the form and the content of this paper. 


\section{References.}

[1] R\&D Proposal for the Study of New Fast and Radiation Hard Scintillators for Calorimetry at LHC, Crystal Clear Collaboration, CERN-DRDC/91-15 (1991); Crystal Clear Collaboration Status Report, CERN-DRDC/93-31 (1993).

[2] CMS collaboration, CMS Letter of Intent, CERN-LHCC/92-3 (1992).

[3] G. Stevenson, in : Proc. Large Hadron Collider Workshop, vol.3, eds G. Jarlskog and D. Rein, CERN/90-10, ECFA/90-133 (1990) 566-583.

[4] P.A. Aarnio and M. Huhtinen, Nucl. Inst. and Meth. A336 (1993) 98-105.

[5] Crystal Clear Collaboration, Further Results on Cerium Fluoride Crystals, Nucl. Inst. and Meth. A322 (1993) 373-394.

[6] F. De Notaristefani, personal communication.

[7] Présentation du Réacteur Ulysse, INSTN note, unpublished.

[8] L. Granberg, G. Frye, N. Nereson and L. Rosen, Phys. Rev. 103 (1956) 662-670.

[9] see, for example, J. Moteff, Reactor Neutron Dosimetry in Irradiation of Materials, in : Radiation Dosimetry, vol. 3, $2^{\mathrm{d}}$ edition, eds F.H. Attix and E. Tochilin (Academic Press, New-York, 1969) p. 201-245.

[10] N.E. Holden, in : CRC Handbook of Physics and Chemistry, $73^{\text {rd }}$ edition, ed. D.R. Lide (CRC Press, Boca-Raton, 1992).

[11] measured with a Nardeux, type 31A, babyline, across $7 \mathrm{mg} / \mathrm{cm}^{2}$. 
